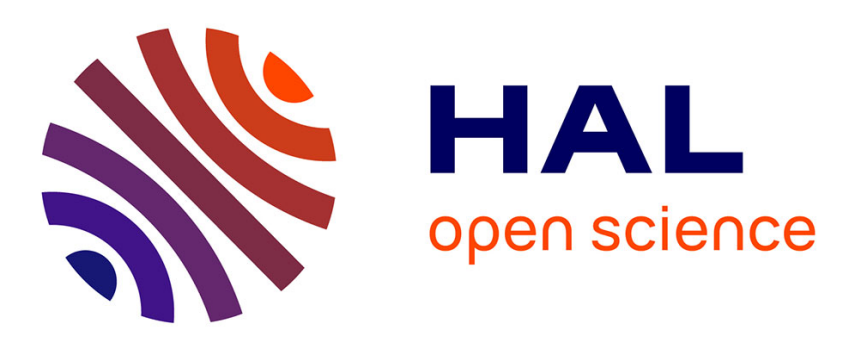

\title{
Biomimetic Tough Gels with Weak Bonds Unravel the Role of Collagen from Fibril to Suprafibrillar Self-Assembly
}

Milena Lama, Biravena Raveendranathan, Julie Brun, Francisco M C Fernandes, Cedric Boissiere, Nadine Nassif, Alba Marcellan

\section{To cite this version:}

Milena Lama, Biravena Raveendranathan, Julie Brun, Francisco M C Fernandes, Cedric Boissiere, et al.. Biomimetic Tough Gels with Weak Bonds Unravel the Role of Collagen from Fibril to Suprafibrillar Self-Assembly. Macromolecular Bioscience, 2021, pp.2000435. 10.1002/mabi.202000435 . hal03219149

\section{HAL Id: hal-03219149 \\ https://hal.sorbonne-universite.fr/hal-03219149}

Submitted on 6 May 2021

HAL is a multi-disciplinary open access archive for the deposit and dissemination of scientific research documents, whether they are published or not. The documents may come from teaching and research institutions in France or abroad, or from public or private research centers.
L'archive ouverte pluridisciplinaire HAL, est destinée au dépôt et à la diffusion de documents scientifiques de niveau recherche, publiés ou non, émanant des établissements d'enseignement et de recherche français ou étrangers, des laboratoires publics ou privés. 


\section{Biomimetic Tough Gels with Weak Bonds Unravel the Role of Collagen from Fibril to Suprafibrillar Self-Assembly}

Milena Lama, Biravena Raveendranathan, Julie Brun, Francisco M. Fernandes, Cédric Boissière, Nadine Nassif,* and Alba Marcellan*

Dr. M. Lama, B. Raveendranathan, J. Brun, Dr. F.M. Fernandes, Pr. C. Boissière, Dr. N. Nassif Sorbonne Université, CNRS, Collège de France

Laboratoire Chimie de la Matière Condensée de Paris

4 place Jussieu F-75005 Paris, France

E-mail: nadine.nassif@sorbonne-universite.fr

Dr. M. Lama, J. Brun, Dr. A. Marcellan

Sciences et Ingénierie de la Matière Molle

ESPCI Paris, PSL University, CNRS, Sorbonne Université

10 rue Vauquelin, F-75005 Paris, France

E-mail: alba.marcellan@espci.psl.eu

Dr. A. Marcellan

Institut Universitaire de France (IUF), 1, rue Descartes, F-75005 Paris, France

Keywords: collagen, gels, self-assembly, mechanical behavior, microstructure, biomimetism

Biological tissues rich in type I collagen exhibit specific hierarchical fibrillar structures together with remarkable mechanical toughness. However, the role of collagen alone in their mechanical response at different structural levels is not fully understood. Here, we propose to rationalize such challenging interplay from a materials science perspective through the subtle control of this protein self-assembly in vitro. We rely on a spray-processing approach to readily use the collagen phase diagram and set a palette of biomimetic self-assembled collagen gels in terms of suprafibrillar organization. Their mechanical responses unveil the involvement of mechanisms occurring either at fibrillar or suprafibrillar scales. Noticeably, both modulus at early stage of deformations and tensile toughness probe the suprafibrillar organization, while durability under cyclic loading and stress relaxation reflect mechanisms at the fibril level. By changing the physico-chemical environment, we modify the interfibrillar interactions towards more biomimetic mechanical responses. The possibility to make tissue-like materials with versatile compositions and toughness opens perspectives in tissue engineering. 


\section{Introduction}

Soft matter science and engineering has been particularly inspired by living matter ${ }^{[1]}$ to develop synthetic soft and 'smart' materials using macromolecular and supramolecular chemistries. ${ }^{[2,3]}$ Analogs of metabolic processes were introduced such as stimuli-responsive motions, ${ }^{[4]}$ self-healing ${ }^{[5]}$ or mechanical training and learning capabilities. ${ }^{[6,7]}$ By capitalizing on strategies observed in nature such as the sacrificial bond concept, ${ }^{[8]}$ toughness and damage tolerance of conventional synthetic gels were improved by covalent or physical bond breaking. ${ }^{[9,10]}$ In parallel, other attempts have been performed by using natural polymers ${ }^{[1]}$ to mimic more closely the performances of biological materials.

The abundance of type I collagen in extracellular matrices (ECM) of vertebrates, the diversity of ultrastructures that it forms and its functions in vivo ${ }^{[12]}$ testify to the scientific interest towards this protein from both fundamental and applicative points of view. Many attempts have been made in the biomaterial field to propose collagen gels for tissue repair. ${ }^{[13]}$ By taking advantage of in vitro collagen liquid crystal properties, ${ }^{[14]}$ tissue-like ultrastructures have been reproduced. ${ }^{[15,16]}$ Indeed, the phase diagram of collagen molecules in vitro consists of mesophases, arising from spontaneous self-assembly modulated by $\mathrm{pH}$ and ionic strength ${ }^{[17]}$ which resemble ECM organizations above $4 \mathrm{wt} \%$. Up to now, four collagen mesophases have been identified: nematic (N) just above $4 \mathrm{wt} \%$ where alignment domains resemble the fibrillar arrangement in dermis, precholesteric* $\left(\mathrm{P}^{*}\right)$ around $4.5 \mathrm{wt} \%^{[18]}$ as cornea-like plywood, precholesteric (P) below $8 \mathrm{wt} \%$ as tendon-like crimp morphology and cholesteric (C) above 8 wt\% as bone-like twisted plywood. Such organizations were shown to be stabilized by a solgel transition triggered through a $\mathrm{pH}$ increase. ${ }^{[19]}$ Three dimensional materials characterized by a high density and subsequent hierarchically ordered collagen fibrils are obtained following different procedures proposed in the literature. ${ }^{[20]}$ Because of a sharp increase in viscosity entailed by strong supramolecular interactions, the precise control of collagen concentration in highly concentrated collagen gels remains challenging. Yet, the setting of a palette of tough 
collagen gels with physical bonds is of high importance for the understanding of the structureproperties relationship in biological tissues; and more specifically of their mechanical response. Noticeably, it was shown that synthetic collagen material with bone-like features exhibits higher stiffness with a low rate of mineral (organic/inorganic ratio $94: 6 \mathrm{wt} \%)^{[21]}$ than a collagen matrix fully mineralized (organic/inorganic ratio 75:25 wt\%). ${ }^{[22]}$ This provided experimental evidence for the common statement that collagen micro-architecture is the most important criteria to assess bone mechanical performance. The fact that native collagen-rich tissues are much more complex in composition, e.g. proteoglycans, ${ }^{[23]}$ chemical crosslinks evolving with time, ${ }^{[24]}$ variability due to the anatomic location $^{[25]}$ and anisotropy ${ }^{[26]}$ complexifies the discrimination of the role of collagen at its diverse hierarchical levels.

Here, we propose a simple manufacturing method to prepare type I collagen gels as models to study the intricate interplay between collagen fibril to suprafibrillar self-assembly and mechanical response in biological materials. We capitalize on the previously described process to prepare non-denatured collagen microparticles by spray-drying ${ }^{[27]}$ to produce $3 \mathrm{D}$ tissue-like collagen gels in terms of fibrillar microstructure. The approach is bioinspired, relying on the secretion of collagen by cells to form the ECM. The different models were validated thanks to their biomimetic microstructures and their non-linear mechanical response at large strain, characteristic of fibrillar collagen gels. ${ }^{[28]}$ Free of covalent crosslinks and other ECM components, the comparison between collagen and gelatin gels- where both the fibrillar and the suprafibrillar levels are absent-demonstrates that fibrillar self-assembly promotes the formation of tough hydrogels. Using such tissue-like collagen models, we probe different hierarchical levels with relevant mechanical loading that further lead us to infer the role of other ECM components by comparison with the mechanical response of biological tissues. Overall, the work offers a versatile platform to better understand the structure-properties relation in collagen-based ECM. 


\section{Setting a Palette of 3D Biomimetic Collagen gels as Tissue Analogues}

Purified acidic (molecular) collagen solutions were prepared from rat tail tendons (see Methods). As depicted in Figure 1a, dense collagen microparticles were produced by spraydrying $^{[27]}$ and mixed with acetic acid aqueous solution. The rationale in using this method is that a simple weighing of the collagen microparticles determines the concentration of the gel. A series of collagen gels was obtained by targeting a wide range of concentration to scan the phase diagram. ${ }^{[16]}$ Seven different concentrations were fixed i.e. 1.8, 2.7, 3.6, 4.5, 5.4, 6.3 and $7.2 \mathrm{wt} \%$ of collagen, by taking into account the presence of about $10 \mathrm{wt} \%$ water in the collagen microparticles. ${ }^{[27]}$ The concentrated collagen solutions were then set into a silicone-and-glass cubic centimeter mold. In order to induce the sol-gel transition, the surrounding $\mathrm{pH}$ was increased by ammonia vapor which diffused through the silicone mold without changing the concentration. Increasing the $\mathrm{pH}$ resulted in the precipitation of the collagen molecules into collagen fibrils by supramolecular self-assembly, leading to the formation of typical crossstriated fibrils as observed by Transmission Electron Microscopy (TEM) (Figure 1b). For gels with concentration above $4 \mathrm{wt} \%$, the in vitro fibrillogenesis step fixes as well the suprafibrillar network topology. ${ }^{[19]}$ Samples were then rinsed in aqueous solvent before characterization in order to reach a neutral $\mathrm{pH}$.

The fibrillar microstructure was assessed by TEM observations. As shown in Figure 1c, at $2.7 \mathrm{wt} \%$ fibrils are randomly distributed as expected since the concentration is below the isotropic/anisotropic transition. Some aggregates are also observed locally. At $4.5 \mathrm{wt} \%$, interestingly, the plywood organization reported in self-assembled collagen matrices mimicking the ultrastructure of cornea ${ }^{[18]}$ is reproduced. Nevertheless, the thickness of the sample (too low) precludes conclusion on its transparency (Figure S1). And indeed, at 7.2 wt\%, a wavy pattern characteristic of the precholesteric organization is observed in the sample. As suggested by the strong differences in opacity of the matrices (Figure S1), the most concentrated 
collagen gels exhibit submicron-sized heterogeneities due to partially dissolved collagen microparticles (see also observation by Scanning Electron Microscopy (SEM) in Figure S2). This is also reflected by the observations of highly oriented domains, e.g. alignment between partially dissolved microparticles (Figure 1c) and cholesteric patterns (Figure S3).

In summary, TEM observations strongly suggest that the phase diagram of collagen remains unchanged with this new process of matrices' elaboration, thus confirming the reliability of the processing strategy.

\section{Initial Stiffness and Tensile Toughness Probe Suprafibrillar Organization}

Adapted mechanical testing conditions were developed to explore the mechanical response of the gels in hydrated state according to the phase diagram. Drying of the samples was considered as negligible during testing timespan (less than $3 \%$ ). Since the gels are dissolved at low $\mathrm{pH}$ (Figure S4), it is worth reminding that only physical supramolecular interactions govern their integrity from molecular to macroscopic scale. The tensile behavior is non-linear (Figure 2a), exhibiting a J-shaped stress-strain curve which is a common feature of soft biological tissues, ${ }^{[29]}$ fibrillar collagen gels ${ }^{[30]}$ and hydrated collagen fibrils themselves ${ }^{[31]}$. Thus, in addition to TEM observations, this result shows that characteristic features of biological ECM are reproduced only through collagen self-assembly in water and noticeably, without requiring widely used chemical crosslinkers such as aldehydes. ${ }^{[32]}$ During the early stages of deformation (toe region), mechanical response is assigned to the unfolding of the collagen molecule ends present in the gap regions. ${ }^{[28]}$ At large strains, strain-hardening (linear region) is observed. The physical crosslinks, which may break and form again during stretching of the material, enable gliding at molecular and fibril scales. ${ }^{[28]}$ Figure 2a, inset compares the tensile response of collagen and gelatin gels. In the case of gelatin, the irreversible partial denaturation of the native collagen triple helix into a more random coiled structure prevents the self-assembly into hierarchical structures. Therefore, gelatin gels rather exhibit a conventional 
rubber-like (non-hookean) stress-strain response. The rigidity of collagen and gelatin gels increases with their concentration (Figure 2b), within the investigated concentration range. Discrepancies are enhanced at higher collagen concentrations, possibly due to local variations in concentration from the incomplete dissolution of collagen microparticles mentioned above (Figure S1). Besides, this can also arise from random shearing effects owing to injection above the liquid crystal threshold. However, for the same concentration and comparable composition, collagen gels exhibit higher stiffness (c.a. by one order of magnitude) than gelatin gels. In addition, unlike gelatin gels for which elastic modulus scales linearly with concentration, collagen gels display a non-linear dependency presumably assigned to their fibrillar nature ${ }^{[33]}$ rather than to their assembly at higher scale.

To go deeper in the understanding of the relationship between non-linear tensile response and the gels ultrastructure, further investigations were performed on three gels being representative of the different organizations in the collagen diagram, namely isotropic (2.7 $\mathrm{wt} \%), \mathrm{P}^{*}(4.5 \mathrm{wt} \%)$ and $\mathrm{P}(7.2 \mathrm{wt} \%)$. Given the thickness of the mold $(\sim 2 \mathrm{~mm})$, the ammonia vapors exposure time was fixed at 3 hours, determined experimentally as the minimum time to obtain sample-scale gelation $\left(\sim 1 \mathrm{~mm} \mathrm{~h}^{-1}\right) \cdot{ }^{[34]}$ Collagen microparticles dissolution time was fixed at $30 \mathrm{~min}$ in order to enable collagen molecules self-assembly within a controlled timespan. As shown in Figure 2c, the tensile behavior is highly reproducible for the three investigated concentrations demonstrating the reliability of our set-up (see Methods). Inspired by the nonlinear elasticity of soft tissues, ${ }^{[29]}$ the tensile curves were fitted with an exponential equation:

$$
\sigma(\varepsilon)=A\left(\exp \left(\varepsilon / \varepsilon_{\text {hard }}^{*}\right)-1\right)
$$

where $A$ (in $\mathrm{kPa}$ ) and $\varepsilon_{\text {hard }}^{*}$ are positive constants, $\sigma$ is the nominal stress (in $\mathrm{kPa}$ ) and $\varepsilon$ the strain; $\varepsilon_{\text {hard }}^{*}$ defines a characteristic strain at which strain hardening operates. The exponential fit provides a description of experimental data by $\varepsilon_{\text {hard }}^{*}$ identification (Table 1). By comparison with the two other concentrations, the strain-hardening for $7.2 \mathrm{wt} \%$ collagen is less pronounced 
within the investigated strain. The fact that partially dissolved microparticles remain at this concentration as observed by electron microscopies, possibly reduces the relative mobility of the collagen fibrils. This could prevent efficient interfibrillar gliding shifting hardening processes at higher strains thus increasing $\varepsilon_{\text {hard }}^{*}$.

Measured values of stress at break (often defined as ultimate tensile strength, UTS) are $73.3 \pm 21.9 \mathrm{kPa}, 159.4 \pm 18.9$ and $173.7 \pm 26.3 \mathrm{kPa}$ at $2.7,4.5$ and $7.2 \mathrm{wt} \%$, respectively (Figure 2d). Interestingly, the UTS values at $4.5 \mathrm{wt} \%$ and $7.2 \mathrm{wt} \%$ are higher than that of dense but not self-assembled collagen gels (100 $\mathrm{kPa}$ at $12 \mathrm{wt} \%$ of collagen) ${ }^{[33]}$ The stress at break of the collagen gels show a substantial increase $(p<0.05)$ after the isotropic/anisotropic threshold, like toe modulus $(p<0.0001)$ (Figure $2 \mathrm{~d}$ ) that emphasizes the effect of suprafibrillar assembly. The fracture energy on notched specimen appears less sensitive to the isotropic/anisotropic threshold but increases significantly at higher concentrations $(\mathrm{p}<0.001)$ along with toe modulus $(\mathrm{p}<0.05)$. This feature strongly contrasts with the fracture behavior of rubber-like materials like synthetic gels. Their threshold fracture energy scales with $E^{-1 / 2[35]}$ meaning that increasing rigidity has a detrimental effect on fracture resistance. Nevertheless, even taking into account the great variabilities in toughness in literature and the associated difficulty to make an estimate independent on geometry, the toughness of the collagen gels $\left(40-100 \mathrm{~J} \mathrm{~m}^{-2}\right)$ is rather low compared to that expected for biological soft tissues $\left(\mathrm{kJ} \mathrm{m}^{-2}\right) \cdot{ }^{[36]}$ This may be explained by the presence of hierarchical organization at higher levels in biological tissues, together with other components and covalent crosslinks. Optimizing the process for promoting anisotropy at higher scale in the collagen gels could improve their efficiency in slowing down crack propagation, like in macroscopically organized tissues such as tendons. ${ }^{[37]}$

In summary, the collagen gels exhibit tissue-like tensile response related to their microstructure where addition of biological components should improve their mechanical 
performances to reach that of biological tissues. Thus, they offer a reliable model upon which we investigated further the role of collagen in the ECM at different hierarchical fibrillar levels.

\section{Long Term Stability and Durability of the Collagen Gels Reflect Mechanisms at the} Fibril Level

Long-term stability was first experienced by soaking the gels for weeks to months in sterile milliQ water (Figure S5). As depicted in Figure 3a, collagen concentration after swelling remained within $7 \%$ difference of their initial concentration, indicating that the process preserved gel integrity by providing strong fibrillar interactions. This behavior is consistent with previous observations of dense collagen matrices after long-term storage in physiologicallike media. ${ }^{[18,38]}$ The thermal stability of the collagen gels was investigated by differential scanning calorimetry (DSC). As depicted in Figure 3b, gels display an endotherm at $52{ }^{\circ} \mathrm{C}$ characteristic of fibrillar collagen denaturation. ${ }^{[39]}$ The estimated values of enthalpy, around 36$40 \mathrm{~J} \mathrm{~g}^{-1}$ for all concentrations, are commensurable with that of rat tail tendon (around $54 \mathrm{~J} \mathrm{~g}^{-}$ $\left.{ }^{1}\right) .{ }^{[40]}$ Physical interactions in the collagen gels at fibril scale appear strong enough to sustain tissue-like durability, in agreement with their swelling behavior.

Fatigue tests were carried out to assess gel durability under cyclic strain. An immersion cell was designed (Figure 3c, inset), filled with phosphate buffer saline (PBS) to control the long term environment of the gel upon cycling and tend to a more physiological environment. After being equilibrated in PBS for at least two weeks, gels were clamped and durability was investigated for 1000 cycles up to a maximal strain of $20 \%$. This strain limit was chosen as a compromise to be sufficiently far from the beginning of the toe region that appears less sensitive to viscoelastic effects (Figure S6) and far from damage mechanisms before failure as well. The total experiment lasted 1.5 hours. For the three concentrations (Figure 3c and Figure S7), collagen gels exhibit typical fatigue behavior of tendons. ${ }^{[41]}$ The first cycle demonstrates hysteresis, followed by cycles presenting a slight residual strain but almost closed-loops and a 
mechanical response well-overlapped without dramatic softening or creeping phenomena over time. Usually, in synthetic materials, damage mechanisms and/or stress relaxation operate during repeated mechanical cycling which result into a decrease in stiffness upon cycling. ${ }^{[42]}$ Here, in contrast, normalized secant modulus of collagen gels initially display a slight increase in rigidity $(12 \pm 3 \%, 7 \pm 1 \%$ and $4 \pm 2 \%$ at gel concentrations $2.7 \mathrm{wt} \%, 4.5 \mathrm{wt} \%$ and $7.2 \mathrm{wt} \%$ respectively) up to an optimum between 50-100 cycles (Figure 3d). It is followed by a continuous decrease in rigidity, presumably due to damage mechanisms. Such behavior may be due to training capabilities as reported in synthetic gels. ${ }^{[6,7]}$ Noticeably, tendons exhibit such a behavior with a stiffness increase of $18 \pm 11 \% .{ }^{[43]}$ In fact, the observed reinforcement could possibly arise from interactions at fibril scale. ${ }^{[44]}$ More specifically, it could be due to a lateral fusion of fibril units as reported in dense but not self-assembled collagen gels. ${ }^{[45]}$ Such preeminence of physical interactions at fibril scale is consistent with the plotted dissipated strain energy densities for the three concentrations (Figure S8): they merge into a master curve after normalization by the area under the loading curve (Figure 3e). An alternative hypothesis would be that the moderate strain loading is too low to trigger suprafibrillar mechanisms. Nevertheless, potential screening effects induced by PBS ions in the medium cannot be excluded, as they are likely to occur in physiological conditions. Therefore, covalent crosslinks in ECM could help maintain tissue integrity and mechanical properties towards cyclic loadings (Figure 3e, scheme).

In order to probe time-dependent deformation mechanisms at a strain level of $20 \%$, collagen gels were submitted to stress-relaxation tests. As plotted in Figure S9, collagen gels exhibit a tissue-like viscoelastic response. ${ }^{[46]}$ When plotted on a log-log scale, the three concentrations show a similar decay with time (Figure $3 \mathrm{f}$ ), with a slope equal to $n=-$ $0.081 \pm 0.006$. This value is comparable to those obtained for tendons ( $n=-0.051$ to -0.113 ) stretched at physiological strains (2-6\%, within the toe region). ${ }^{[47]}$ Besides, stress-time curves 
normalized by peak stress at all concentrations collapse into a master curve (Figure 3g), which suggests that strain accommodation could proceed by the same dynamics and presumably same mechanism. Therefore, it appears that (i) suprafibrillar structure has little influence on stressrelaxation behavior i.e. time-dependent phenomenon are likely to occur at fibril scale, and (ii) pure collagen matrices seem to display intrinsic viscous dissipation mechanisms regardless of the presence of other ECM components. In biological tissues, this behavior is most probably modulated by the surrounding non-fibrillar matrix rich in polysaccharides such as glycosaminoglycans (GAGs) (Figure 3g, scheme), which interact with the fibril surface. ${ }^{[48,49]}$

In summary, the time-dependent response of the collagen gels appears to reflect mechanisms at the fibril scale as schematically illustrated in Figure 3. It highlights the need for covalent crosslinks and/or other ECM components (e.g. GAGs) in the mechanical performances of biological tissues. One step further, we decided to modify the physical interactions at the fibril scale in order to probe their influence on the mechanical behavior.

\section{Tuning Interfibrillar Interactions Towards More Biomimetic Mechanical Responses}

First, we explored the influence of PBS ionic species on the tensile behavior of gels at $4.5 \mathrm{wt} \%$ and compared it to that of pig cornea. Collagen gels were immersed and equilibrated in PBS after in vitro fibrillogenesis in ammonia vapors at standard conditions (3 h). Unlike gels equilibrated in milliQ water, they are more compliant in the toe region thus closer to the behavior of pig cornea (Figure 4a). In fact, such collagen gels have a lower concentration at equilibrium (around $2.7 \mathrm{wt} \%$ ), indicating that they tend to swell more than gels stored in milliQ water. Besides, their tensile behavior is close to that of a collagen gel at $2.7 \mathrm{wt} \%$ stored in milliQ water. Interestingly, collagen gels synthesized by fibrillogenesis in PBS and stored in PBS also tend to be more compliant. Their concentration at equilibrium is around $3.7 \mathrm{wt} \%$. In addition, DSC thermograms (Figure 4b) show that the use of phosphate buffer leads to two endothermal peaks $\left(\mathrm{T}=43{ }^{\circ} \mathrm{C}\right.$ and $\left.\mathrm{T}=52{ }^{\circ} \mathrm{C}\right)$ versus one at $52{ }^{\circ} \mathrm{C}$ in milliQ water. This suggests 
that phosphate ions adsorbed onto fibrils weaken interfibrillar interactions by recruiting water molecules ${ }^{[50]}$ and/or modifying the surface charge of fibrils thus increasing macroscopic gel swelling together with osmotic effects. Interestingly, SEM observations reveals an heterogeneity in fibril thickness when PBS is used (Figure 4c) suggesting that each endothermal peak is assigned to a different fibril population namely lower thickness at $52{ }^{\circ} \mathrm{C}$ (white star) and higher thickness at $43{ }^{\circ} \mathrm{C}$ (white arrow) (Figure $4 \mathrm{~b}-\mathrm{c}$ ). This is in agreement with previous works in the literature reporting that $(i)$ phosphate and sodium ions influence fibril morphology in low concentrated collagen gels ${ }^{[51]}$ and (ii) at specific ionic strengths, dense collagen gels exhibits two fibril populations in terms of thickness. ${ }^{[52]}$ This indicates that, even after in vitro fibrillogenesis, potential ion-induced structural modifications during storage can participate in gel softening. Such phenomenon is likely to occur since sodium ions are described to modulate mechanical properties of naturally cross-linked ECM. ${ }^{[23]}$ By evidencing that the mechanical response is driven here by both the homogeneity in fibril size and the nature of ionic species (Figure $4 \mathrm{~b}$, scheme) as reported in vivo, ${ }^{[23,53]}$ we show that it is possible to discriminate the implication of collagen at the fibril scale in the mechanical response of biological tissues.

It is worth mentioning that changing the exposure time to ammonia vapors from $3 \mathrm{~h}$, to $15 \mathrm{~h}$ and $48 \mathrm{~h}$ using the same initial collagen concentration (4.5 wt\%) resulted in slight differences in the non-linear stress-strain response (Figure 4d) but almost identical toe modulus (Figure S10). As reported in Table 2, $\varepsilon_{\text {hard }}^{*}$ increases with increasing times of fibrillogenesis suggesting that interfibrillar gliding at the origin of strain-hardening becomes less efficient. Besides, the enthalpy of denaturation increases as well (Figure $4 \mathrm{e}$ ), from $47 \pm 2 \mathrm{~J} \mathrm{~g}^{-1}$, to $67 \pm 2 \mathrm{~J}$ $\mathrm{g}^{-1}$ and $71.5 \pm 0.5 \mathrm{~J} \mathrm{~g}^{-1}$ after $3 \mathrm{~h}, 15 \mathrm{~h}$ and $48 \mathrm{~h}$ ammonia exposure times, respectively. Both tend to show a reinforcement of supramolecular interactions. In fact, different stages of aggregation during self-assembly process of collagen molecules into fibrils are identified in vitro ${ }^{[54]}$ including microfibrils. ${ }^{[55]}$ Thus, at constant collagen concentration, an increase in fibril 
thickness possibly occurs with increasing times of fibrillogenesis (Figure 4d-e, scheme) as previously observed. ${ }^{[56]}$

Finally, the stress-strain response of pig cornea exhibits dramatic non-linearity: low toe modulus followed by a linear modulus that remains orders of magnitude greater than that of our collagen gels. This strain-hardening could be explained by $(i)$ the presence of an additional nonfibrillar matrix in the cornea (e.g. proteoglycans) promoting stiffness, ${ }^{[23]}$ and/or (ii) a suprafibrillar organization at larger scale in cornea, while our gels are composed of locally anisotropic domains randomly distributed in the bulk.

In summary (Figure 4f), modifying fibrillogenesis and post-fibrillogenesis conditions enable us to propose a palette of concentrated collagen matrices (diamonds) with mechanical properties close to those of biological tissues (circles). Like non-self-assembling processing approaches in the literature (triangles), our system is highly versatile and exhibits higher stiffnesses than other self-assembled collagen matrices (squares). Besides possible processing improvements (e.g. dissolution time of microparticles), going beyond $7.2 \mathrm{wt} \%$ in collagen concentration opens perspectives to reach mechanical performances closer to those of tendons or blood vessels.

\section{Conclusion}

We have set a range of tough collagen matrices characterized by different fibrillar microstructures, which geometries follow that described in the molecular collagen phase diagram. They qualitatively exhibit mechanical responses mimicking those of biological tissues, enabling to discriminate the implication of intra- and interfibrillar interactions, and of suprafibrillar assembly. Adding organic additives (such as polysaccharides, non-collagenous proteins) or mineral to mimic more closely various biological tissues will open perspectives for a better understanding of the structure-property interplay in collagen-based ECM. Noticeably, 
their use as cell culture substrates could provide local information for tissue-adapted cell behavior. ${ }^{[57]}$ 


\section{Experimental section}

Synthesis of concentrated collagen gels: Collagen solutions were extracted and purified from rat tail tendons following a procedure described elsewhere. ${ }^{[17]}$ Collagen microparticles were formed by using a Büchi B290 mini spray-drier following a procedure described elsewhere. ${ }^{[27]}$ The resulting collagen powder was weighed to determine the final concentration $(1.8 \mathrm{wt} \%$ to $7.2 \mathrm{wt} \%$ ) and mixed with acetic acid at low concentration. Two protocols were used for gel synthesis. For the first series of gels: the solution was placed in a syringe and injected into a home-made silicone mold $\left(15 \times 25 \times 2 \mathrm{~mm}^{3}\right)$ through a $26 \mathrm{G}$ needle. Fibrillogenesis was performed by increasing $\mathrm{pH}$ up to 9-10 units by ammonia vapor diffusion ${ }^{[19]}$ overnight. Then, gels were directly placed in sterile phosphate buffer and stored at $4{ }^{\circ} \mathrm{C}$. For the other series: the solution was centrifuged for 2 minutes at $26000 \mathrm{~g}$ at $4{ }^{\circ} \mathrm{C}$ in order to remove air bubbles. The solution was then spread in the silicone mold (same dimensions) by using a spatula. Fibrillogenesis was performed by increasing $\mathrm{pH}$ up to $9-10$ units by ammonia vapor diffusion ${ }^{[19]}$ for $3 \mathrm{~h}, 15 \mathrm{~h}$ or $48 \mathrm{~h}$. Then, gels were thoroughly rinsed with sterile milliQ water or sterile PBS until the surrounding $\mathrm{pH}$ stabilized around 6-7 units, and further stored in sterile milliQ water or sterile PBS at $4{ }^{\circ} \mathrm{C}$. For the fibrillogenesis in PBS, specifically designed immersion molds were used, consisting in two 3D-printed plastic frames covered with $3.5 \mathrm{kDa}$ dialysis membrane sandwiching a $2 \mathrm{~mm}$ thick silicone spacer. After centrifugation, collagen solutions were carefully spread in the mold in sterile conditions. After sealing, the immersion mold was placed for 4 days in a PBS bath at $4{ }^{\circ} \mathrm{C}$. Collagen gels were then removed and stored in sterile PBS at $4{ }^{\circ} \mathrm{C}$.

Mechanical characterizations: Mechanical tests were performed with an Instron tensile testing machine (models 5565 and 5965) equipped with a $10 \mathrm{~N}$ load cell (with relative uncertainty of $0.16 \%$ ) and Bluehill software. Gels were punched at the following dimensions: $20 \mathrm{~mm}$ x $5 \mathrm{~mm}$ x $2 \mathrm{~mm}$. For the first series of collagen gels, tensile tests were performed on hydrated samples 
(3 specimen per condition) at room temperature using home-made clamps recovered with white Velcro-like grips, at a strain rate of $0.06 \mathrm{~s}^{-1}$. The deformation was followed using a video extensometer (relative uncertainty of $0.11 \%$ at full scale), by putting two separated white dots on the sample. After the first series, new clamps were engineered with a striated surface to avoid slippage. Their efficiency was verified by using the extensometer with collagen gels at various concentrations. An optimal tightening torque was determined at $7 \mathrm{cN} \mathrm{m}{ }^{-1}$, to hold the sample by preventing slippage and without damaging it. Negligible slippage was observed after analysis. Such conditions were used for tensile tests for the other collagen gels series and gelatin gels ( 2 to 3 specimen per condition). Stress-relaxation tests were performed at room temperature on hydrated samples ( 3 specimen per condition). A loading ramp at $0.6 \mathrm{~s}^{-1}$ was imposed from 0 $\%$ to $20 \%$ strain, then the sample was held at $20 \%$ strain for 400 s. Drying of the collagen samples was considered as negligible during this time span (less than $3 \%$ weight loss). Cyclic tests were performed by placing the striated clamps holding the sample in a home-designed chamber containing phosphate buffer at room temperature. Collagen samples were equilibrated at least two weeks in phosphate buffer prior to the test (2 to 3 specimen per condition). Cyclic loading was performed at a strain rate of $0.06 \mathrm{~s}^{-1}$, up to $20 \%$ deformation, down to $0 \mathrm{~N}$, during 1000 cycles. The mean buoyancy was subtracted from the measured force induced by the sample by running the test without sample for 10 cycles (minimum condition set at initial sample length), keeping the same volume of phosphate buffer in the chamber. All data were analyzed using IgroPro software. The toe modulus of the collagen gels was measured by a linear fit within the first $20 \%$ deformation. The linear modulus of the collagen gels was measured by a linear fit within the last $10 \%$ of the stress-strain curve before failure. The elastic modulus of the gelatin gels was calculated by a linear fit within the first $10 \%$ deformation of the stressstrain curve. 
Comparative statics: analyses were based on Student's $t$-test with two-tailed distribution. A pvalue $<0.05$ was considered statistically significant.

More information about other materials (gelatin gels, pig cornea) and characterizations (DSC, TGA, collagen gel concentration, swelling and dissolution, SEM and TEM preparation and observations) can be found in the Supporting Information.

\section{Acknowledgements}

The authors thank Bernard Haye for his help in TEM preparation. This work was supported by French state funds managed by the ANR within the Investissements d'Avenir programme under reference ANR-11-IDEX-0004-02, and more specifically within the framework of the Cluster of Excellence MATISSE led by Sorbonne Universités. N. Nassif acknowledges Fondation Collège de France and Fondation EDF.

\section{References}

[1] C. Sanchez, H. Arribart, M. M. Giraud Guille, Nat. Mater. 2005, 4, 277.

[2] M. J. Webber, E. A. Appel, E. W. Meijer, R. Langer, Nat. Mater. 2015, 15, 13.

[3] B. R. Freedman, D. J. Mooney, Adv. Mater. 2019, 31, 1.

[4] S. Bauer, S. Bauer-Gogonea, I. Graz, M. Kaltenbrunner, C. Keplinger, R. Schwödiauer, Adv. Mater. 2014, 26, 149.

[5] L. Leibler, P. Cordier, C. Soulie, Nature 2008, 451, 977.

[6] T. Matsuda, R. Kawakami, R. Namba, T. Nakajima, J. P. Gong, Science 2019, 363, 504.

[7] S. Lin, J. Liu, X. Liu, X. Zhao, Proc. Natl. Acad. Sci. 2019, 116, 10244.

[8] G. E. Fantner, T. Hassenkam, J. H. Kindt, J. C. Weaver, H. Birkedal, L. Pechenik, J. A. Cutroni, G. A. G. Cidade, G. D. Stucky, D. E. Morse, P. K. Hansma, Nat. Mater. 2005, $4,612$.

[9] J. P. Gong, Y. Katsuyama, T. Kurokawa, Y. Osada, Adv. Mater. 2003, 15, 1155.

[10] S. Rose, A. Prevoteau, P. Elzière, D. Hourdet, A. Marcellan, L. Leibler, Nature 2014, 
$505,382$.

[11] S. Van Vlierberghe, P. Dubruel, E. Schacht, Biomacromolecules 2011, 12, 1387.

[12] P. Fratzl, Collagen: Structure and Mechanics, Springer, Boston, MA 2008.

[13] M. M. Giraud Guille, N. Nassif, F. M. Fernandes, Mater. Des. Inspired by Nat. Funct. Through Inn. Archit. 2013, 107.

[14] M. M. Giraud-Guille, J. Mol. Biol. 1992, 224, 861.

[15] M.-M. Giraud-Guille, Mol. Cryst. Liq. Cryst. Inc. Nonlinear Opt. 1987, 153, 15.

[16] M. M. Giraud-Guille, L. Besseau, Connect. Tissue Res. 1998, 37, 183.

[17] F. Gobeaux, E. Belamie, G. Mosser, P. Davidson, P. Panine, M. M. Giraud-Guille, Langmuir 2007, 23, 6411.

[18] C. Salameh, F. Salviat, E. Bessot, M. Lama, J.-M. Chassot, E. Moulongui, Y. Wang, M. Robin, A. Bardouil, M. Selmane, F. Artzner, A. Marcellan, C. Sanchez, M.-M. GiraudGuille, M. Faustini, R. Carminati, N. Nassif, Proc. Natl. Acad. Sci. 2020, 117, 202001178.

[19] L. Besseau, M. M. Giraud-Guille, J. Mol. Biol. 1995, 251, 197.

[20] G. Griffanti, S. N. Nazhat, Int. Mater. Rev. 2020, 65, 502.

[21] N. Nassif, F. Gobeaux, J. Seto, E. Belamie, P. Davidson, P. Panine, G. Mosser, P. Fratzl, M. M. Giraud Guille, Chem. Mater. 2010, 22, 3307.

[22] S. Heinemann, C. Heinemann, M. Jäger, J. Neunzehn, H. P. Wiesmann, T. Hanke, ACS Appl. Mater. Interfaces 2011, 3, 4323.

[23] S. Akizuki, V. C. Mow, F. Müller, J. C. Pita, D. S. Howell, D. H. Manicourt, J. Orthop. Res. 1986, 4, 379.

[24] A. J. Bailey, Mech. Ageing Dev. 2001, 122, 735.

[25] A. Karimi, M. Navidbakhsh, Ski. Res. Technol. 2015, 21, 149.

[26] A. N. Annaidh, K. Bruyère, M. Destrade, M. D. Gilchrist, M. Otténio, J. Mech. Behav. 
Biomed. Mater. 2012, 5, 139.

[27] M. Lama, F. M. Fernandes, A. Marcellan, J. Peltzer, M. Trouillas, S. Banzet, M. Grosbot, C. Sanchez, M. M. Giraud-Guille, J. J. Lataillade, B. Coulomb, C. Boissière, N. Nassif, Small 2020, 16, 1902224.

[28] P. Fratzl, K. Misof, I. Zizak, G. Rapp, H. Amenitsch, S. Bernstorff, J. Struct. Biol. 1997, $122,119$.

[29] Y. Fung, Am. J. Physiol.1967, 213, 1532.

[30] B. A. Roeder, K. Kokini, J. E. Sturgis, J. P. Robinson, S. L. Voytik-Harbin, J. Biomech. Eng. 2002, 124, 214.

[31] J. A. J. Van Der Rijt, K. O. Van Der Werf, M. L. Bennink, P. J. Dijkstra, J. Feijen, Macromol. Biosci. 2006, 6, 699.

[32] K. Madhavan, D. Belchenko, A. Motta, W. Tan, Acta Biomater. 2010, 6, 1413.

[33] N. O. Kamranpour, A. K. Miri, M. James-Bhasin, S. N. Nazhat, Biofabrication 2016, 8, 015018.

[34] F. Gobeaux, PhD Thesis, Sorbonne Université (Paris, France), September, 2007.

[35] G. J. Lake, A. G. Thomas, Proc. R. Soc. London. Ser. A. Math. Phys. Sci. 1967, 300, 108.

[36] P. P. Purslow, J. Mater. Sci. 1983, 18, 3591.

[37] R. F. Ker, Int. J. Fatigue 2007, 29, 1001.

[38] Y. Wang, J. Silvent, M. Robin, F. Babonneau, A. Meddahi-Pelle, N. Nassif, M. M. G. Guille, Soft Matter 2011, 7, 9659.

[39] E. I. Tiktopulo, A. V. Kajava, Biochemistry 1998, 37, 8147.

[40] C. A. Miles, T. V. Burjanadze, A. J. Bailey, J. Mol. Biol. 1995, 245, 437.

[41] T. W. Herod, S. P. Veres, J. Orthop. Res. 2018, 36, 467.

[42] X. Zhao, Soft Matter 2014, 10, 672.

[43] D. T. Fung, V. M. Wang, N. Andarawis-Puri, J. Basta-Pljakic, Y. Li, D. M. Laudier, H. 
B. Sun, K. J. Jepsen, M. B. Schaffler, E. L. Flatow, J. Biomech. 2010, 43, 274.

[44] M. E. Susilo, J. A. Paten, E. A. Sander, T. D. Nguyen, J. W. Ruberti, Interface Focus 2016, 6, 20150088.

[45] U. Cheema, C. B. Chuo, P. Sarathchandra, S. N. Nazhat, R. A. Brown, Adv. Funct. Mater. 2007, 17, 2426.

[46] P. P. Purslow, T. J. Wess, D. W. Hukins, J. Exp. Biol. 1998, 201, 135.

[47] S. E. Duenwald, R. Vanderby, R. S. Lakes, Ann. Biomed. Eng. 2009, 37, 1131.

[48] R. Puxkandl, I. Zizak, O. Paris, J. Keckes, W. Tesch, S. Bernstorff, P. Purslow, P. Fratzl, Philos. Trans. R. Soc. B Biol. Sci. 2002, 357, 191.

[49] H. R. C. Screen, J. Seto, S. Krauss, P. Boesecke, H. S. Gupta, Soft Matter 2011, 7, 11243.

[50] C. A. Miles, N. C. Avery, V. V. Rodin, A. J. Bailey, J. Mol. Biol. 2005, 346, 551.

[51] T. Hayashi, Y. Nagai, J. Biochem. 1974, 76, 177.

[52] F. Gobeaux, G. Mosser, A. Anglo, P. Panine, P. Davidson, M. M. Giraud-Guille, E. Belamie, J. Mol. Biol. 2008, 376, 1509.

[53] V. Ottani, M. Raspanti, a Ruggeri, Micron 2001, 32, 251.

[54] A. R. McCluskey, K. S. W. Hung, B. Marzec, J. O. Sindt, N. A. J. M. Sommerdijk, P. J. Camp, F. Nudelman, Biomacromolecules 2020, 21, 3631.

[55] D. A. Cisneros, C. Hung, C. M. Franz, D. J. Muller, J. Struct. Biol. 2006, 154, 232.

[56] Y. Li, A. Asadi, M. R. Monroe, E. P. Douglas, Mater. Sci. Eng. C 2009, 29, 1643.

[57] A. J. Engler, S. Sen, H. L. Sweeney, D. E. Discher, Cell 2006, 126, 677.

[58] T. A. Wren, S. A. Yerby, G. S. Beaupré, D. R. Carter, Clin. Biomech. 2001, 16, 245.

[59] D. Shin, T. Finni, S. Ahn, J. A. Hodgson, H. D. Lee, V. R. Edgerton, S. Sinha, J. Appl. Physiol. 2008, 105, 1179.

[60] M. R. Bryant, K. Szerenyi, H. Schmotzer, P. J. McDonnell, Investig. Ophtalmol. Vis. Sci. 1994, 35, 30222 . 
[61] A. P. Ebrahimi, J. Vasc. Interv. Neurol. 2009, 2, 155.

[62] V. Hasirci, N. Hasirci, Fundamentals of Biomaterials, Springer New York, 2018.

[63] A. Brunon, K. Bruyère-Garnier, M. Coret, J. Biomech. 2010, 43, 2221.

[64] A. Karimi, A. Shojaei, Dig. Dis. 2018, 36, 150.

[65] A. Karimi, R. Razaghi, Technol. Heal. Care 2018, 26, 963.

[66] C. E. Ghezzi, B. Marelli, N. Muja, S. N. Nazhat, Acta Biomater. 2012, 8, 1813.

[67] S. Ramtani, Y. Takahashi-Iñiguez, C. Helary, D. Geiger, M. M. Giraud-Guille, J. Mech. Med. Biol. 2010, 10, 35. 

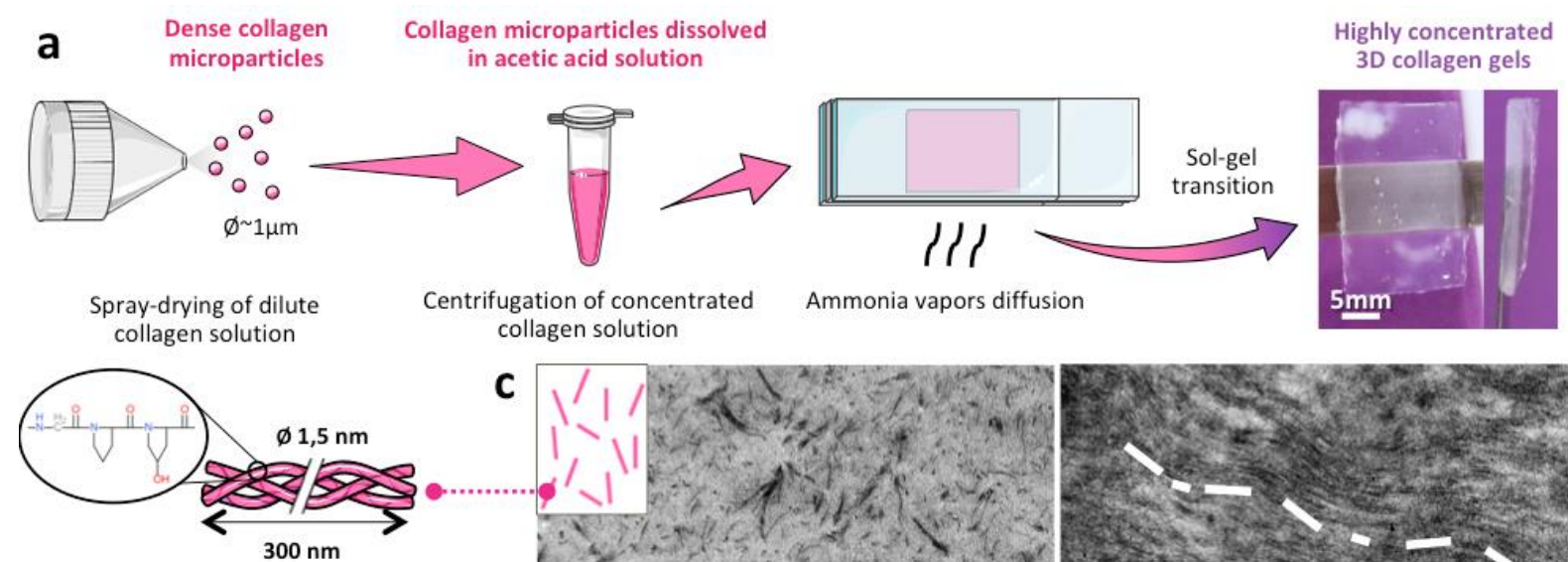

Molecular scale
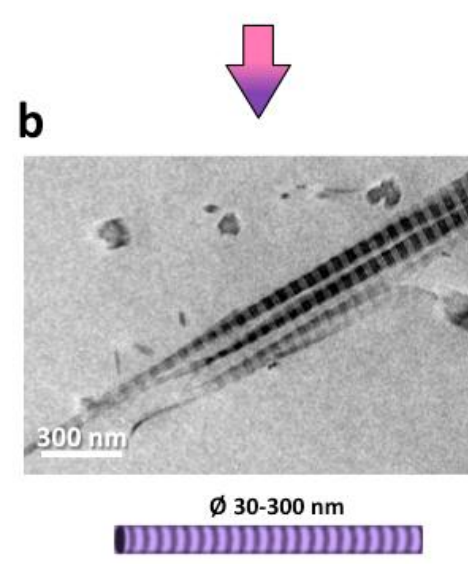

Fibril scale
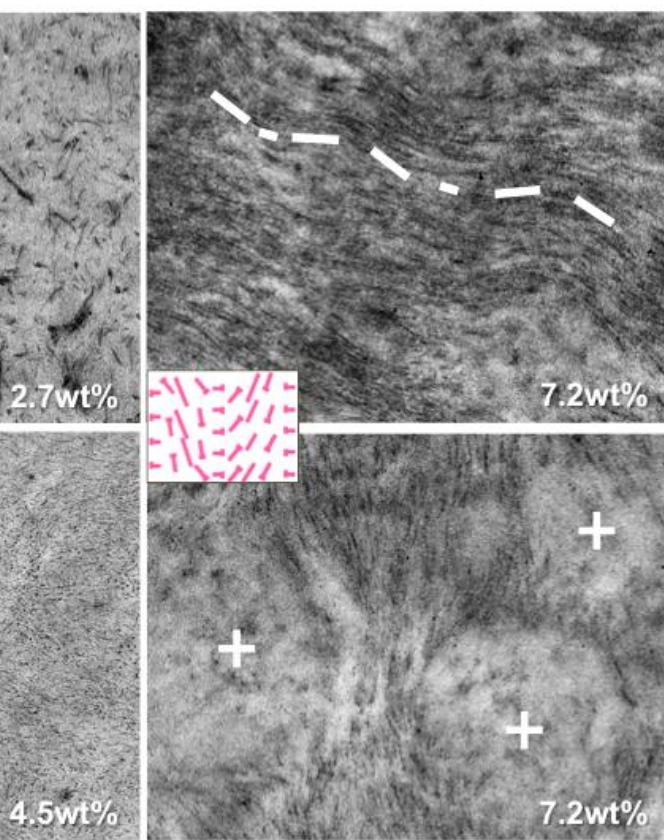

Suprafibrillar scale

Figure 1. a) Schematic of the process for setting highly concentrated collagen gels. First, an acidic collagen solution (molecular form) is spray-dried to form dense collagen microparticles. The microparticles are mixed with acetic acid aqueous solution and set into a 3D mold after centrifugation to remove air bubbles. The sol-gel transition is induced by ammonia vapors, leading to a $\mathrm{pH}$ increase that precipitates collagen molecules into b) cross-striated fibrils (TEM micrograph), thus stabilizing the 3D collagen gel; c) At suprafibrillar scale, fibrillar patterns resembling those of collagen mesophases in solution (inset in pink) are observed, namely isotropic (top left), precholesteric* (bottom left) and precholesteric (right). Partially dissolved collagen microparticles (white cross) are observed in the most concentrated samples. 

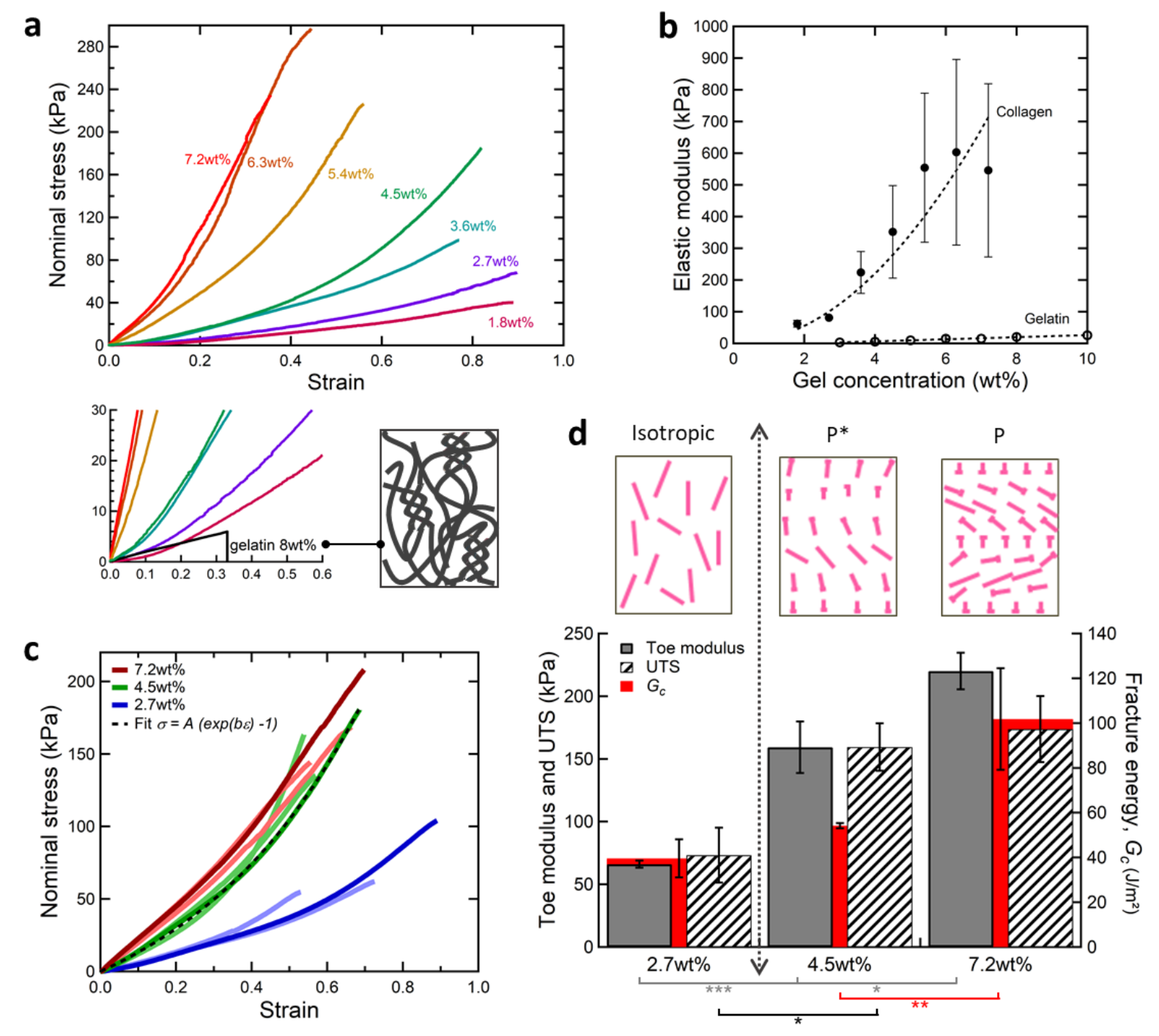

Figure 2. a) Representative stress-strain curves showing J-shaped tensile behavior of the first series of collagen gels from $1.8 \mathrm{wt} \%$ to $7.2 \mathrm{wt} \%$, compared to that of a gelatin gel at $8 \mathrm{wt} \%$ (inset); b) Non-linear increase of linear modulus of first series of collagen gels against concentration, in contrast to that of gelatin gels (dashed lines serve as a guide to the eye); c) Collagen gels at $2.7 \mathrm{wt} \%, 4.5 \mathrm{wt} \%$ and $7.2 \mathrm{wt} \%$ after $3 \mathrm{~h}$ exposure to ammonia vapors show reproducible tensile behavior, the exponential fit is in good agreement with the stress-strain curves; d) Toe modulus and UTS of collagen gels at $2.7 \mathrm{wt} \%, 4.5 \mathrm{wt} \%$ and $7.2 \mathrm{wt} \%$ significantly increase with their respective fracture energy (related to the strain energy required to propagate a crack across sample width) above the isotropic/anisotropic threshold $\left({ }^{*} \mathrm{p}<0.05, * * \mathrm{p}<0.001\right.$, $* * * \mathrm{p}<0.0001)$ 

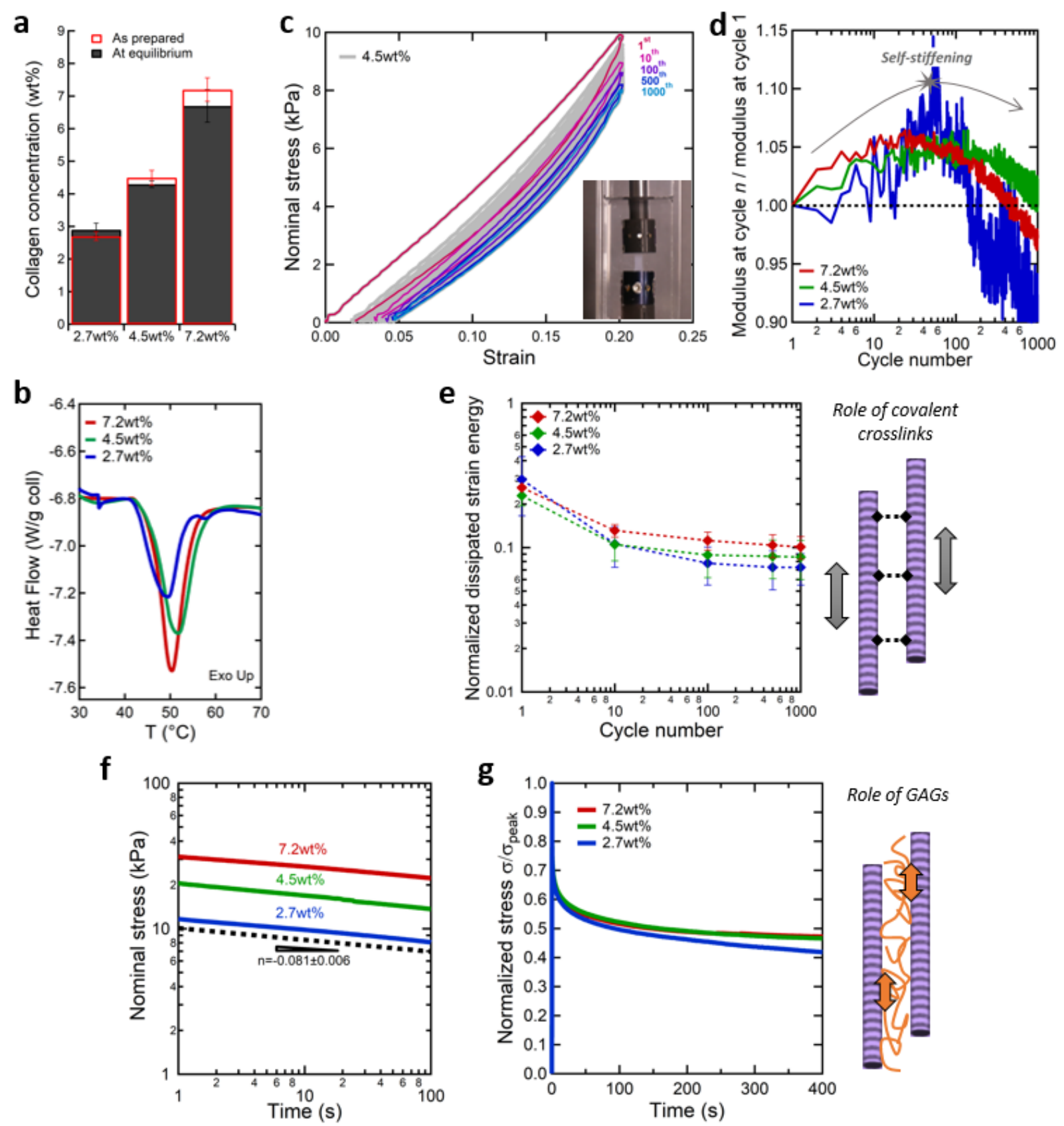

Figure 3. a) Limited swelling of the collagen gels after several weeks in milliQ water; b) Thermal behavior of the collagen gels probed by DSC showing little influence of concentration on denaturation temperature; c) Fatigue behavior of a collagen gel at $4.5 \mathrm{wt} \%$ resembling those of collagen-rich tissues (inset: immersion chamber filled with PBS specifically designed for cyclic tests); d) Secant modulus at $10 \%$ deformation of collagen gels at $2.7 \mathrm{wt} \% 4.5 \mathrm{wt} \%$ and $7.2 \mathrm{wt} \%$ submitted to cyclic testing indicates a self-reinforcement of the gels before damage occurs- the gel at $2.7 \mathrm{wt} \%$ appears to have a more variable behavior; e) Normalized dissipated 
strain energy density corresponding to the area of the loops during cyclic testing of collagen gels at $2.7 \mathrm{wt} \%, 4.5 \mathrm{wt} \%$ and $7.2 \mathrm{wt} \%$ normalized by the area under each loading curve; The scheme highlights the possible role of cross-links in ECM deduced from cycling; f) Log-log plot of stress-relaxation behavior of collagen gels showing the same time-dependency for all concentrations; g) Stress-relaxation curves normalized by peak stress collapse into a master curve. The scheme highlights the possible role of GAGs in ECM during stress accommodation. 

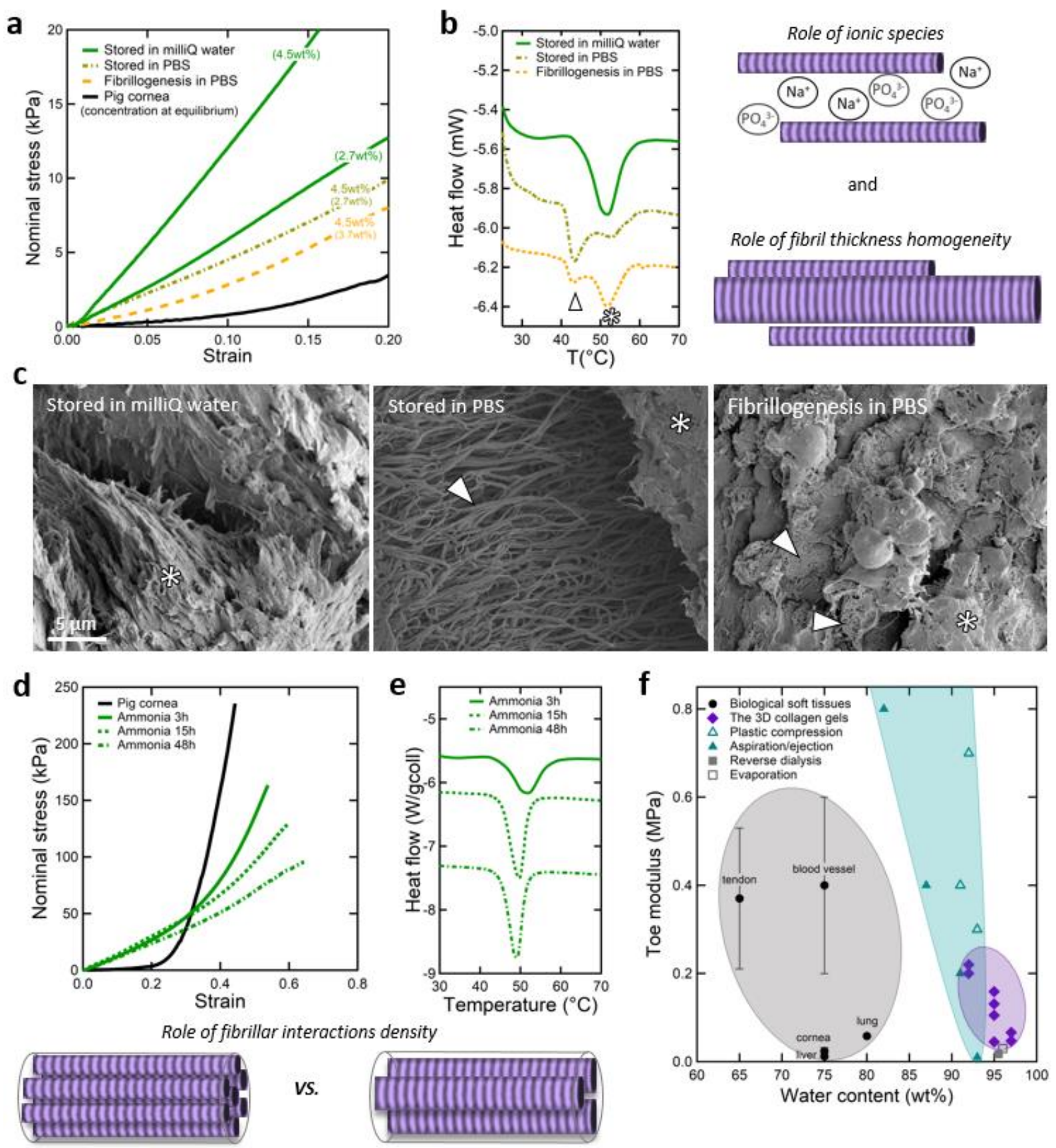

Figure 4. a) Ionic strength and type of ionic species influence tensile response; b) Storage media can induce fibril morphological modifications as evidenced by DSC; Both are illustrated in the scheme; c) SEM micrograph of collagen gels initially at $4.5 \mathrm{wt} \%$ synthesized by fibrillogenesis in ammonia vapors and stored in water (left) or PBS (middle) or synthesized by fibrillogenesis in PBS (right); d) Non-linearity of the tensile response is modulated by the exposure time to ammonia vapors; e) Collagen gels exposed longer to ammonia vapors exhibit higher enthalpy of denaturation; The scheme below (d-e) illustrates possible modifications during fibril 
precipitation; f) Palette of mechanical properties of our collagen gels (diamonds) compared to that of soft biological tissues (circles $)^{[18,58-65]}$ and other collagen processing approaches (triangles and squares) ${ }^{[18,33,66,67]}$ within physiological loadings. 
Table 1. From stress-strain response of collagen gels: measured toe modulus $\mathrm{E}_{\text {toe }}$ (first $20 \%$ deformation), linear modulus $\mathrm{E}_{\text {lin }}$ (last $10 \%$ deformation), ultimate tensile stress, and $\varepsilon_{\text {hard }}^{*}$ obtained as fitting constant from equation (1).

\begin{tabular}{lcccc}
\hline $\begin{array}{l}\text { Collagen gel } \\
\text { concentration }\end{array}$ & \multicolumn{5}{c}{$\mathrm{NH}_{3} 3 \mathrm{~h}$} \\
\hline & $\mathrm{E}_{\text {toe }}$ & $\mathrm{E}_{\text {lin }}$ & UTS & $\varepsilon_{\text {hard }}^{*}$ \\
& {$[\mathrm{kPa}]$} & {$[\mathrm{kPa}]$} & {$[\mathrm{kPa}]$} & \\
$7.2 \mathrm{wt} \%$ & $220.1 \pm 14.6$ & $319.1 \pm 43$ & $173.7 \pm 26.3$ & 1 \\
$4.5 \mathrm{wt} \%$ & $159.3 \pm 20.6$ & $438.7 \pm 125.8$ & $159.4 \pm 18.9$ & 0.36 \\
$2.7 \mathrm{wt} \%$ & $66.1 \pm 2.8$ & $162.4 \pm 39.7$ & $73.3 \pm 21.9$ & 0.5
\end{tabular}

Table 2. From stress-strain response of collagen gels at $4.5 \mathrm{wt} \%$ exposed to different ammonia times: measured toe modulus $\mathrm{E}_{\text {toe }}$ (first $20 \%$ deformation), linear modulus $\mathrm{E}_{\text {lin }}$ (last $10 \%$ deformation), ultimate tensile stress, and $\varepsilon_{\text {hard }}^{*}$ obtained as fitting constant from equation (1).

\begin{tabular}{|c|c|c|c|c|c|c|c|c|c|}
\hline \multirow{2}{*}{$\begin{array}{l}\text { Collagen } \\
\text { gel } \\
\text { concen- } \\
\text { tration }\end{array}$} & \multicolumn{3}{|c|}{$\mathrm{NH}_{3} 3 \mathrm{~h}$} & \multicolumn{3}{|c|}{$\mathrm{NH}_{3} 15 \mathrm{~h}$} & \multicolumn{3}{|c|}{$\mathrm{NH}_{3} 48 \mathrm{~h}$} \\
\hline & $\mathrm{E}_{\text {toe }}$ & $\mathrm{E}_{\text {lin }}$ & $\varepsilon_{\text {hard }}^{*}$ & $\mathrm{E}_{\text {toe }}$ & $\mathrm{E}_{\text {lin }}$ & $\varepsilon_{\text {hard }}^{*}$ & $\mathrm{E}_{\text {toe }}$ & $\mathrm{E}_{\text {lin }}$ & $\varepsilon_{\text {hard }}^{*}$ \\
\hline & {$[\mathrm{kPa}]$} & {$[\mathrm{kPa}]$} & & {$[\mathrm{kPa}]$} & {$[\mathrm{kPa}]$} & & {$[\mathrm{kPa}]$} & {$[\mathrm{kPa}]$} & \\
\hline 4.5 wt\% & $159.3 \pm 20.6$ & $438.7 \pm 125.8$ & 0.36 & $131.4 \pm 19.1$ & $235 \pm 97.1$ & 0.53 & $105 \pm 17.6$ & $135.7 \pm 55.5$ & 1.1 \\
\hline
\end{tabular}




\section{Supporting Information}

\section{Biomimetic Tough Gels with Weak Bonds Unravel the Role of Collagen from Fibril to Suprafibrillar Self-Assembly}

Milena Lama, Biravena Raveendranathan, Julie Brun, Francisco M. Fernandes, Cédric Boissière, Nadine Nassif,* and Alba Marcellan*

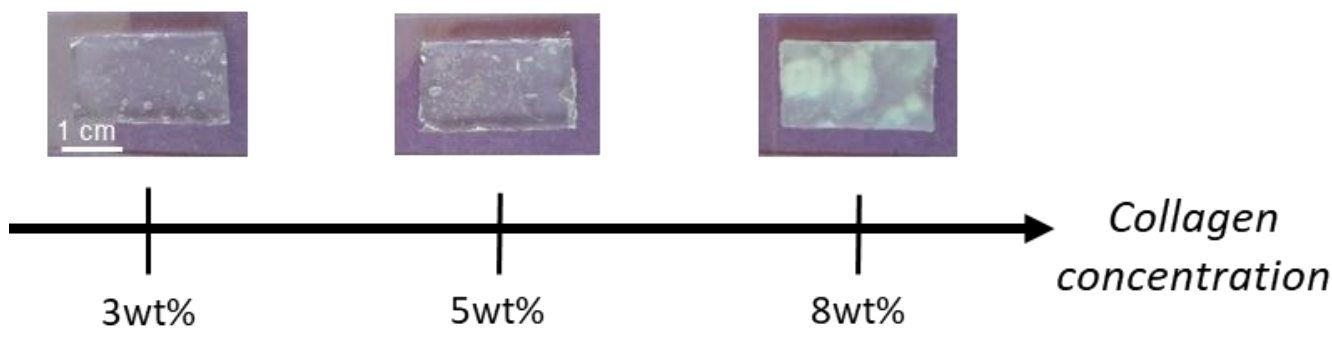

Figure S1. Macroscopic aspect of selected collagen gels. The gels appear transparent at $3 \mathrm{wt} \%$ and $5 \mathrm{wt} \%$, and with opaque domains at $8 \mathrm{wt} \%$.
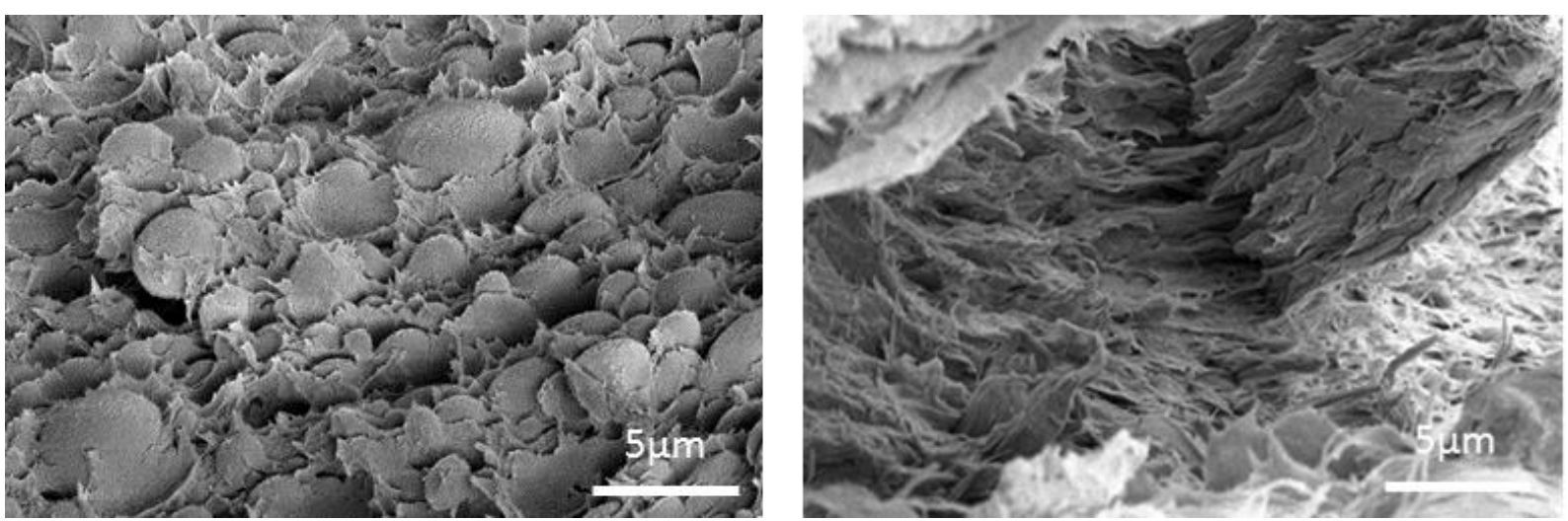

Figure S2. Scanning electron micrograph of a collagen gel at $8 \mathrm{wt} \%$ : partially dissolved collagen microparticles are observed (left), together with aligned fibrillar domains (right). 


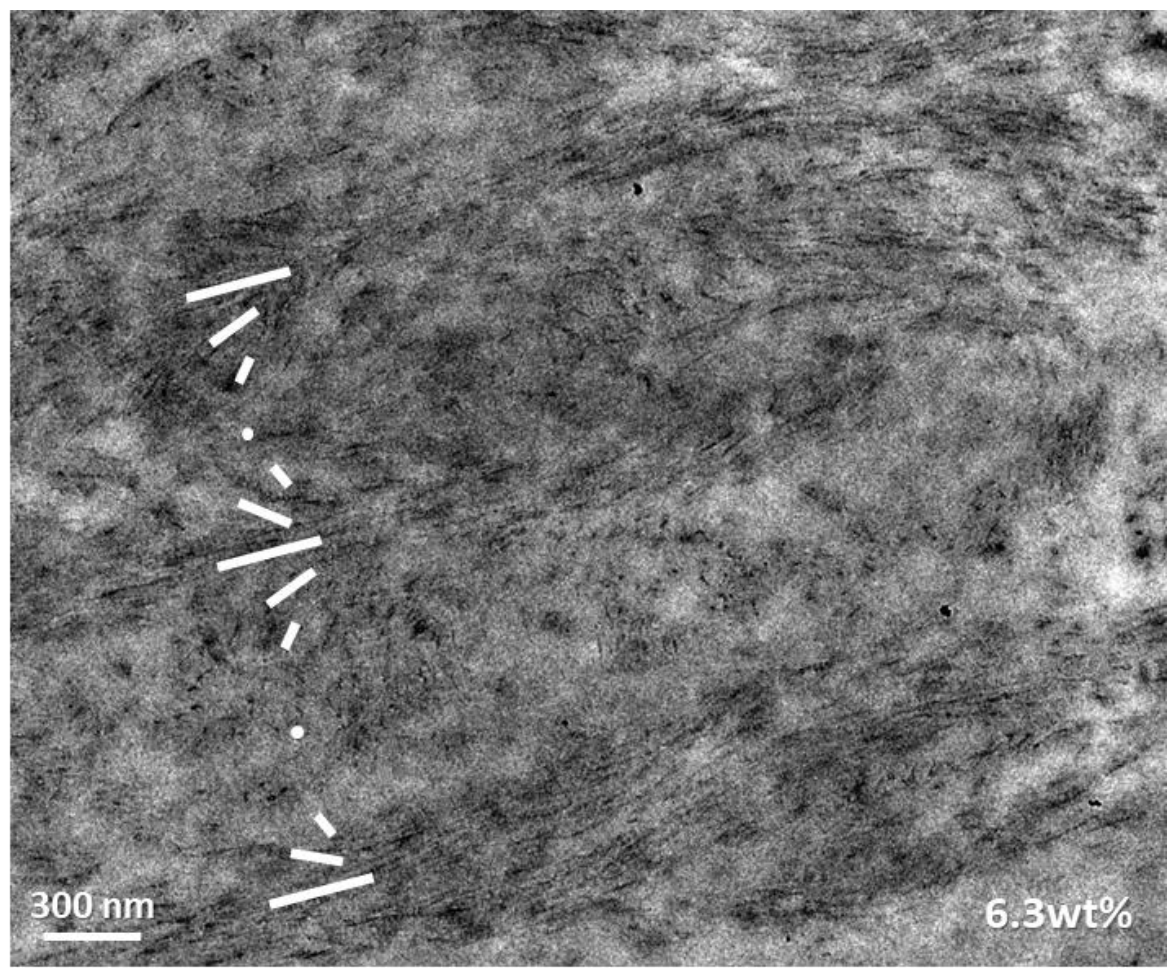

Figure S3. TEM micrograph of a collagen gel at $6.3 \mathrm{wt} \%$ : arched patterns reminding that of cholesteric organization are observed.

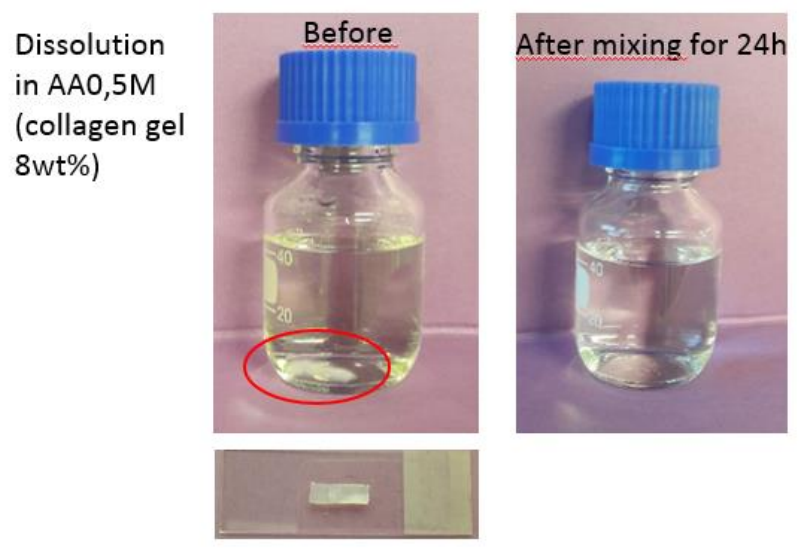

Figure S4. Full dissolution of a piece of collagen gel at $8 \mathrm{wt} \%$ in acidic conditions, showing the reversibility of the physical interactions. 


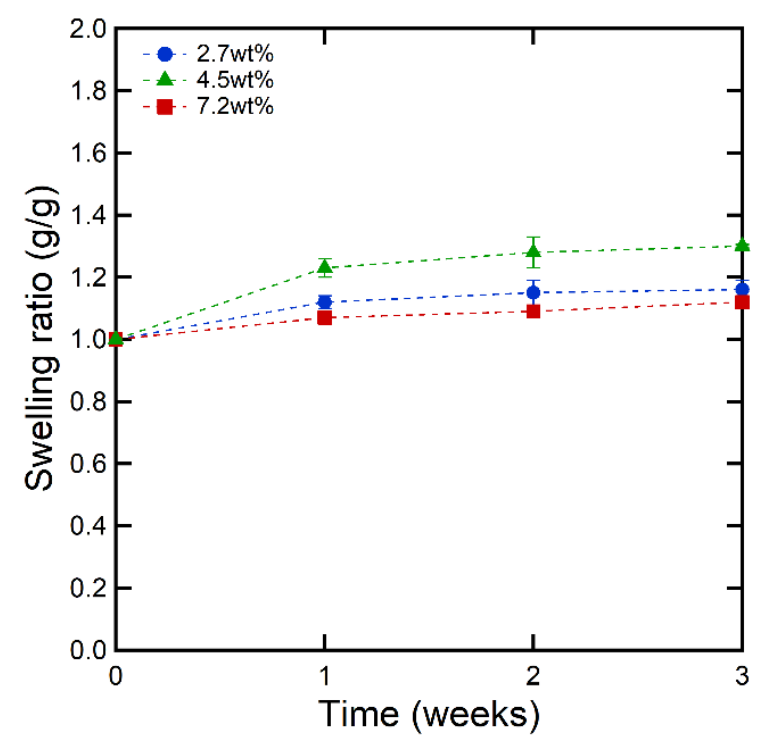

Figure S5. Collagen gels reach equilibrium swelling in milliQ water after 2 weeks.

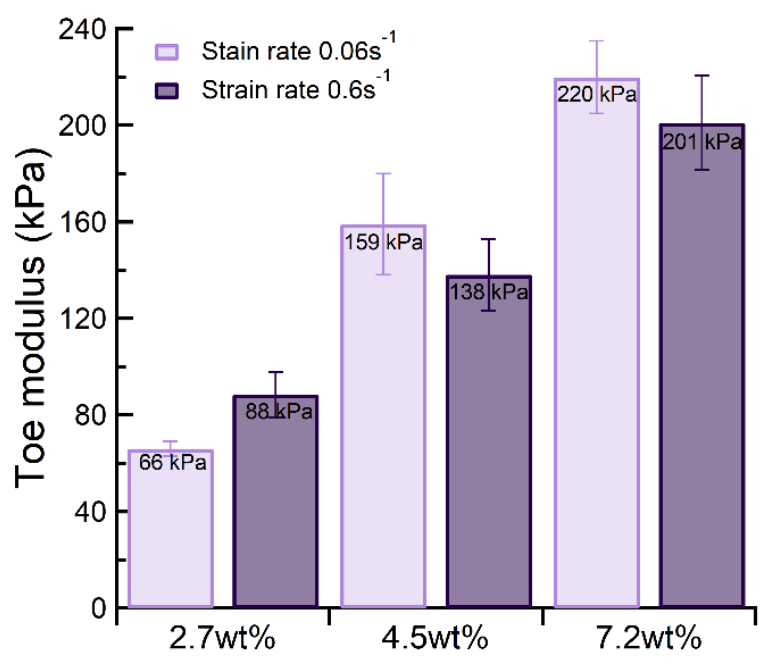

Figure S6. Influence of the tensile strain rate on the toe modulus of the collagen gels. 

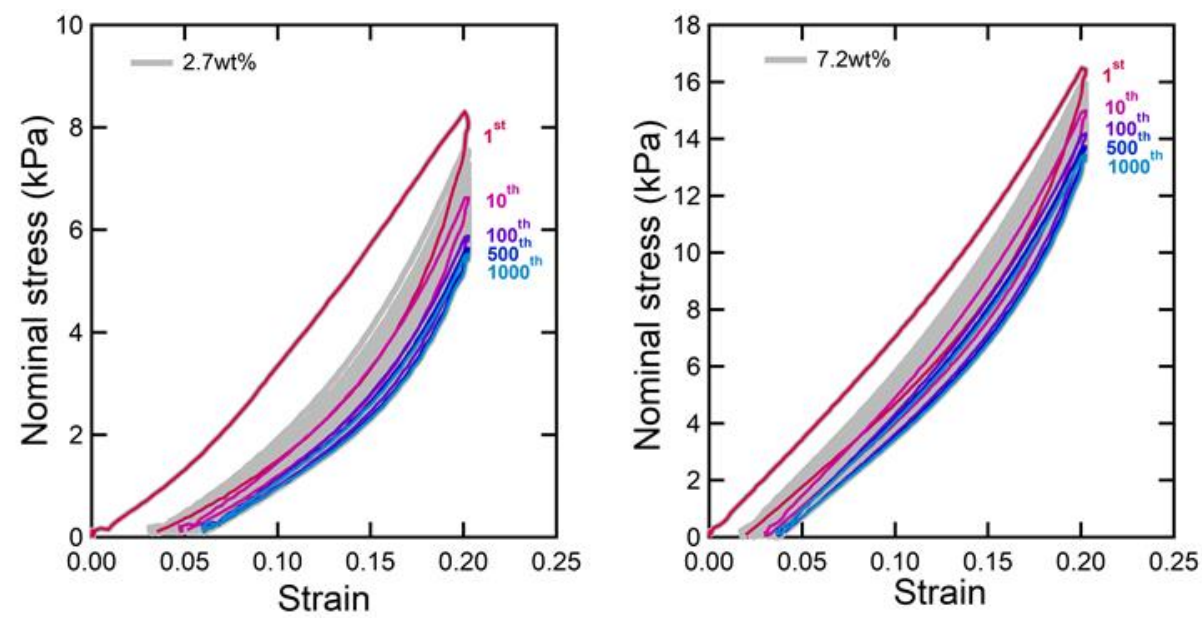

Figure S7. Fatigue behavior of collagen gels at $2.7 \mathrm{wt} \%$ (left) and $7.2 \mathrm{wt} \%$ (right).

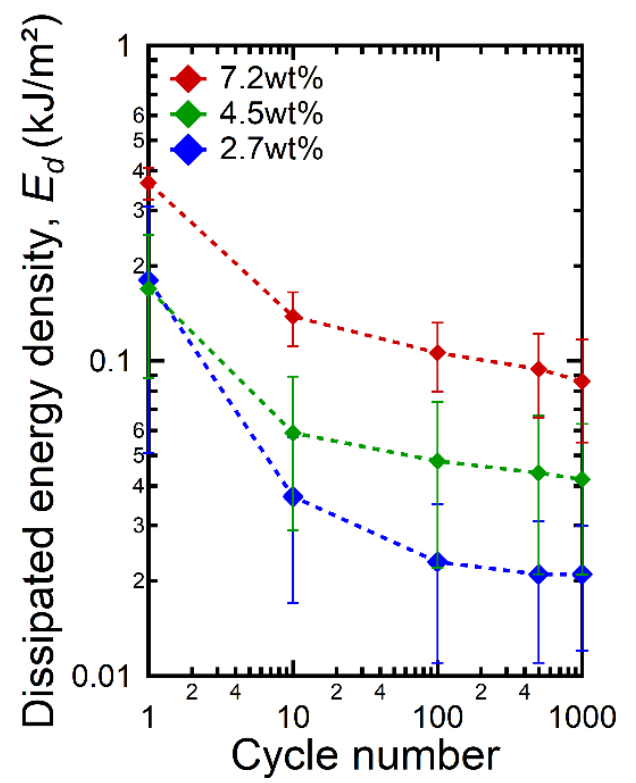

Figure S8. Dissipated strain energy density of collagen gels at $2.7 \mathrm{wt} \%, 4.5 \mathrm{wt} \%$ and $7.2 \mathrm{wt} \%$ corresponding to the area of selected loops. 


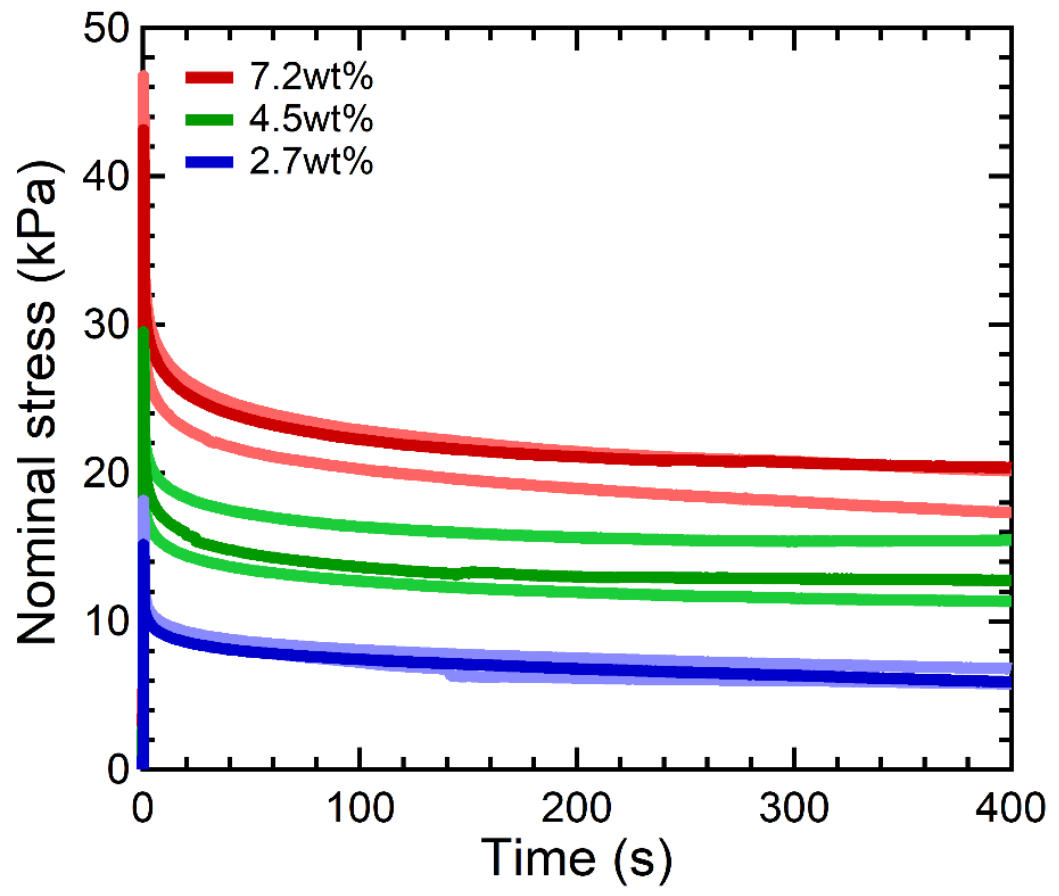

Figure S9. Biomimetic stress-relaxation behavior of collagen gels showing good reproducibility.

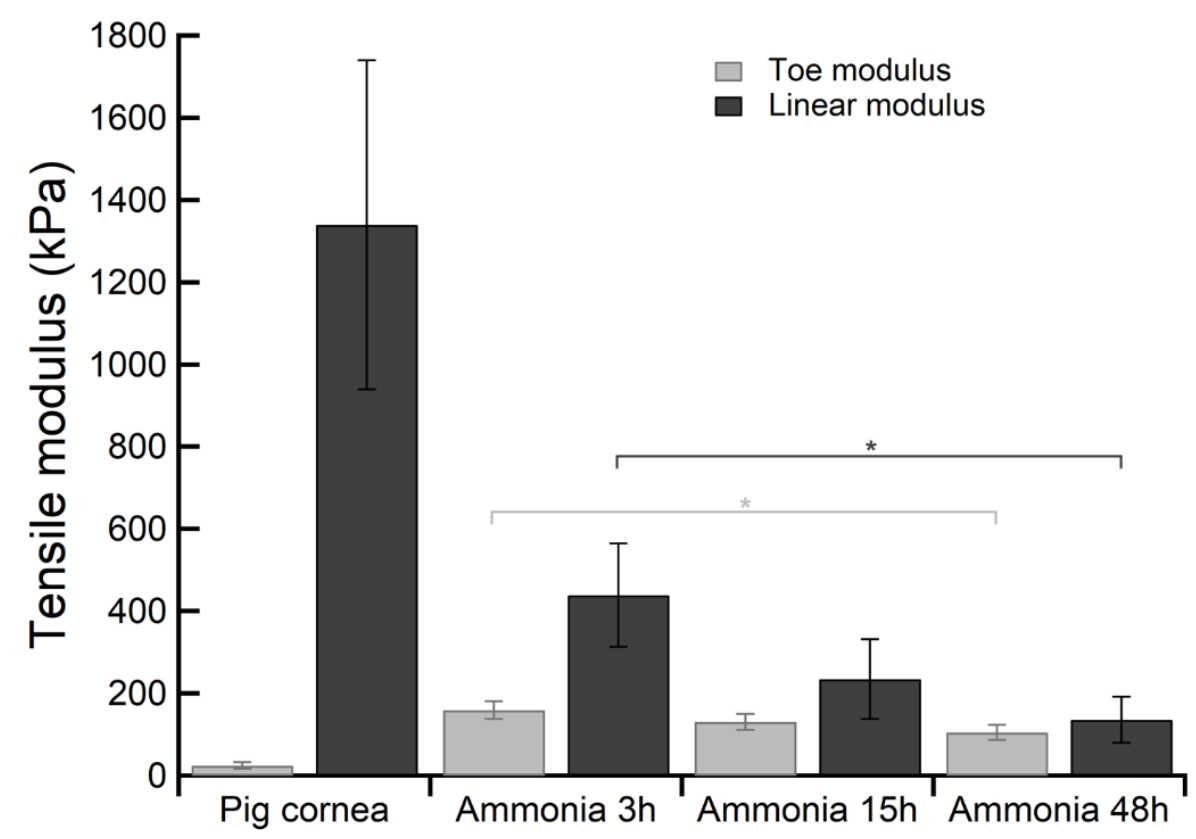

Figure S10. Toe and elastic moduli of collagen gels exposed to different ammonia times, compared to that of pig cornea $(* p<0.05)$. 


\section{Experimental section}

Synthesis of gelatin gels: Type A gelatin (bloom number 300, MW between $50000 \mathrm{~g} \mathrm{~mol}^{-1}$ and $100000 \mathrm{~g} \mathrm{~mol}^{-1}$ ) was purchased from Sigma Aldrich. A desired amount of gelatin corresponding to the final gel concentration (between $3 \mathrm{wt} \%$ and $23 \mathrm{wt} \%$ ) was weighed and mixed with the appropriate volume of milliQ water. The gelatin solution was stirred for at least 2 hours at $55^{\circ} \mathrm{C}$. After full dissolution, the solution was placed in a $2 \mathrm{~mm}$ thick mold recovered with parafilm, left at room temperature for 2 hours and put in the fridge to induce gelation. The gelatin gels were equilibrated at room temperature for 1 hour prior tensile testing.

Pig cornea: The cornea was removed from a 3 months-old pig by a surgeon. Under general anesthesia and in sterile conditions, the cornea at its junction with the sclera was cut at $360^{\circ}$ and stored first in balanced salt solution (ophthalmic irrigation solution), then in Cornea Cold. Differential scanning calorimetry: Experiments were performed with a TA Q-20 machine. The heating rate was set at $5^{\circ} \mathrm{C} \mathrm{min}-1$ and the temperature range from $20^{\circ} \mathrm{C}$ to $80{ }^{\circ} \mathrm{C}$. About $20 \mathrm{mg}$ piece of collagen gel ( 2 to 3 specimen per condition) was quickly blotted with Kimtech paper to remove excess water, weighed and placed in a sealed aluminum pan. An empty sealed aluminum pan was used a reference.

Thermogravimetric analysis (TGA): Experiments were performed with a SDTQ600 machine. After setting the balance to zero, a collagen sample (about $40 \mathrm{mg}$ ) was cut, and quickly blotted with Kimtech paper to remove excess water. The sample was then put in a platinum pan, next to an empty platinum pan as reference. A heating rate of $5^{\circ} \mathrm{C} \mathrm{min}^{-1}$ was used, from room temperature to $650{ }^{\circ} \mathrm{C}$ under air for complete degradation of collagen.

Collagen gel final concentration: Pieces of the collagen gel (2 to 3 specimen per condition) were cut and prepared for TGA according to the protocol described above. After performing the experiment, water content in wt $\%$ was determined from the TGA curve at $200^{\circ} \mathrm{C}$. Indeed, the thermal decomposition of a collagen gel with air takes place in two steps ${ }^{[1]}$ : physisorbed 
water evaporates until $200^{\circ} \mathrm{C}$, then, until $600^{\circ} \mathrm{C}$ collagen is mainly degraded into water and carbon dioxide.

Weighing of samples for swelling measurements: Straight after synthesis, small pieces of collagen gels $\left(\sim 70 \mathrm{~mm}^{3}\right)$ were cut and weighed ( 3 specimen per condition). Then, the pieces were placed in an Eppendorf in sterile milliQ water and weighed at desired time intervals after removing excess water by blotting with Kimtech paper.

Transmission electron microscopy: The collagen gel pieces (2 specimen per condition) were fixed in glutaraldehyde solution $(2.5 \%)$. After washing in cacodylate/saccharose buffer solution, they were post-fixed in osmium tetroxide solution (2\%). After washing, the samples were dehydrated through ethanol baths (from $50 \%$ to $100 \%$ ethanol). Then, they were embedded in araldite resin for ultrathin sectioning $(\sim 70 \mathrm{~nm})$ performed with an Ultracut 7 (Leica), the sections were further deposited on copper grids. Observations were carried out by using a FEI TECNAI G2 Spirit Twin electron microscope operating at 120kV.

Scanning electron microscopy: The collagen gel pieces ( 2 to 3 specimen per condition) were fixed in glutaraldehyde solution $(2.5 \%)$. After washing in cacodylate/saccharose buffer solution, they were dehydrated through ethanol baths (from $30 \%$ to $100 \%$ ethanol). Supercritical $\mathrm{CO}_{2}$ drying was performed by a CPD-300 (Leica). Dried samples were cut into pieces, put on carbon tape covering sample holders, covered with a gold layer $(15 \mathrm{~nm})$. Observations were carried out by using a FEG Magellan 400 FEI Thermofisher microscope operating at $3 \mathrm{kV}$ and $25 \mathrm{pA}$.

Collagen gel dissolution: A piece $\left(\sim 100 \mathrm{~mm}^{3}\right)$ of collagen gel at $8 \mathrm{wt} \%$ was put in acetic acid (0.5 M) and stirred for 24 hours until full dissolution (1 specimen).

\section{References}

[1] L. D. Mkukuma, J. M. S. Skakle, I. R. Gibson, C. T. Imrie, R. M. Aspden, D. W. L. Hukins, Calcif. Tissue Int. 2004, 75, 321. 